\title{
Competent solidarity: the alternative for professional social work
}

\author{
Alastair Russell Auckland Action Against Poverty, Aotearoa New Zealand
}

\begin{abstract}
There is very little evidence of radical politics within social work and community development in Aotearoa/New Zealand where social workers here are caught in the constricting grasp of professionalism. Community development is strictly confined through funder capture and the "no politics" embargo of the Charities Commission. These realities sit comfortably within the oppressions perpetrated by neoliberalism. Professionalism is not compatible with a fight against the neoliberal status quo. The fight against poverty and its social consequences should be the focus of social work and community development. Within the professional paradigm, social workers have become increasingly irrelevant to the people they work with. An alternative paradigm is needed to make social work relevant. The paradigm shift advocated here is to replace professionalism with competent solidarity.

This extended viewpoint article provides a definition of competent solidarity and considers the implications of competent solidarity in Aotearoa/New Zealand. It will then discuss the problems that emerge within professional social work and apolitical community development. Competent solidarity case studies from within Auckland Action Against Poverty are provided and opportunities for future action are discussed.
\end{abstract}

KEYWORDS: competent solidarity; radical social work; activism; neoliberalism; welfare

\section{Introduction}

My thinking around competent solidarity began with a rejection of professional social work. Professional social work is taught as if it exists within a political vacuum, largely devoid of class analysis and is incapable of addressing issues of poverty and oppression. If social workers live in a world of "consensus," then there is no need to choose a side because, in the world of consensus, the interests of the rich and the poor, the coloniser and the colonised are the same. In this world, the distinction between the "professional social worker" and their "client" makes perfect sense. Over the past three years I have supervised 21 students on placements; of these 21 only two started their placements familiar with any conflict theory. They all had knowledge of strategies for individual interventions and of therapies for their clients. Within social work there is a clear emphasis on working with individuals who have a problem, who are deemed to be dysfunctional. In this context, it is easy to ignore the need for social change.

There is a need to include explicit critiques of neoliberal capitalism which link class, poverty, conflict theories and Te Tiriti o Waitangi to provide a solid basis for a more relevant model of social work. In my 30 years of social work experience, I have found most professional social workers to be risk-averse, uncomfortable with conflict and ill-equipped to work within a world characterised by conflict. The professional social worker is likely to be unwilling to explicitly stand alongside someone who is differentiated from them by being their client. To become a professional social worker there is no prerequisite need to have any clarity of
AOTEAROA

NEW ZEALAND SOCIAL WORK 29(2), 137-144.

CORRESPONDENCE TO: Alastair Russell alastair.aaap@gmail.com 
political purpose. Steve Rogowski (a UKbased social work academic), in a review of a book, Class Inequality and Community Development, concludes:

... understanding class is central to grappling with ever increasing inequality and in turn to the theory and practice of community development. And... community work/development is no longer in the repertoire of most social workers. (2017, n.p.)

That community work and community development are no longer in social work's repertoire is a strong indicator that social work is not able to address collective issues. Community agencies are characterised by reliance on government contracts which set out what work can be done. In the current environment, it is necessary to develop and apply explicitly political strategies. Competent solidarity is proposed as an appropriate mode of practice.

\section{Competent solidarity: a definition}

Competent solidarity entails a consciously politicised method of working with people to achieve social change and social justice. It has its ideological underpinnings in anti-capitalist conflict analysis. Capitalism is characterised by conflict between employers and the employed, the rich and the poor, the coloniser and the colonised. There is an explicit understanding that neoliberalism can lead to the wealth of only a privileged few. There are opposing sides and a choice is needed as to whose side you are on. Within social work, individuals are distinct clients. The term client is a clear announcement there is a distinction between that person and the professional. The professional is the expert and the client is the recipient of that expertise. Within this relationship there is no shared interest, and a consequent unwillingness by the professional to take any form of risk. By contrast, competent solidarity encourages public dissent and recognises that political advocacy is integral to this. There is a shared interest between all the people involved.
This separation is exemplified in Ministry of Social Development's Work and Income service which is responsible for administering a complex welfare payment structure within the context of neoliberal welfare reform. Its staff consistently talk about their professionalism and their clients. In my experience, a toxic culture of harassment, intimidation and punishment is camouflaged by this professional/client rhetoric. The reality of the client/professional social worker relationship is similarly camouflaged. Difficulties tend to be located within the client rather than within an institutional structure requiring larger social change. By contrast, a competent solidarity orientation links the experiences of individuals to an analysis of current social issues and identifies opportunities for collective action.

Solidarity includes the ability and willingness to link the experiences and political interests of others to your own experiences and political interests. In this analysis, if others are having their rights denied, so are you, and accordingly you are significantly more likely to question and challenge the status quo. Collective awareness of oppression informs the underlying assumption that political action is needed and will be taken.

\section{Auckland Action Against Poverty (AAAP)}

AAAP is an explicitly political organisation which puts competent solidarity into practice. Competence in this context means having a set of skills, knowledge and experience which will enable engagement with people to address the issues identified by them. Competence will enhance the likelihood of achieving positive outcomes. AAAP was established in 2010 when it became apparent that the government was determined to implement neoliberal welfare reform. AAAP has no government contracts and does not accept funding from any source which will compromise its political purpose. Since 2012, AAAP has provided benefit advocacy as part of a political strategy 
working alongside people experiencing poverty to support them to access their full and correct entitlements. The advocacy service is staffed by a paid coordinator who is a registered social worker and more than 20 volunteer advocates and, in 2017, they will support over 5000 people.

Most of the people we work with are Māori or Pasifika women. The importance of Te Tiriti o Waitangi and 177 years of capitalist, colonial oppression cannot be dismissed, nor can institutional racism and patriarchy which are at the core of social work and community development. People come to AAAP because of their current experience of poverty and of the toxic culture which exists within Work and Income. This is their experience of the economic system; it is their experience of being working class which forms the basis of our shared political interest in changing an oppressive system. This extends far beyond putting a tick on a general election ballot paper every three years.

The practice of competent solidarity requires an understanding of continual colonisation in Aotearoa New Zealand. Te Tiriti o Waitangi was signed to establish a mutually beneficial relationship between peoples, an intention at the core of competent solidarity. Such relationships are not possible within a society based on the exploitation of the poor by the rich, particularly when the rich are predominantly Pākehā and the poor are predominantly Māori. The evidence of institutional racism arising from breaches of Te Tiriti o Waitangi are undeniable (Came, 2012). The use of competent solidarity involves fighting institutional racism layered within economic exploitation.

Neoliberal welfare reform starts from the false assumptions that unemployment is caused by the individual faults of unemployed people and that work is the only pathway out of poverty, whilst ignoring the realities of low-paid, casual work which perpetuates a poverty trap. Benefit advocacy is part of a continuum of political advocacy and is often the beginning of wider political

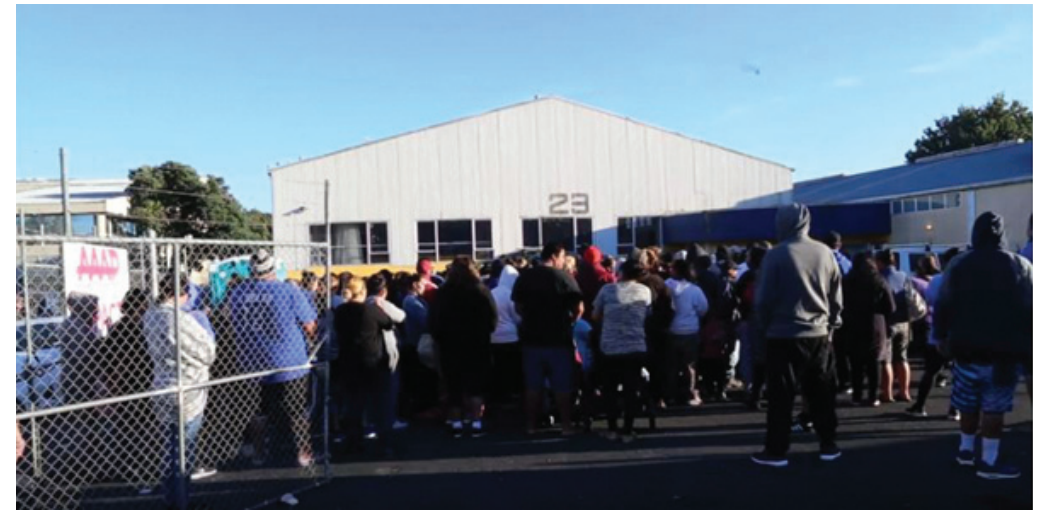

Figure 1. Hundreds of People Waiting to see an Advocate at the AAAP 2016 Benefit Impact in Māngere

action. The numbers of people seen and the high percentage of positive outcomes has given AAAP the credibility to speak publicly about the toxic culture of benefit denial. Further examples of the links between individual benefit advocacy and more obvious political actions will be canvassed in the following discussion, including the Stop the Sanctions campaign and exposure of the exploitative alliance between Work and Income and Manpower (a multi-national recruitment company) which perpetuates the poverty trap of precarious work.

\section{Benefit advocacy}

Benefit advocacy is akin to individual casework. Through the formation of a political alliance between advocates and the people they support, many opportunities for politicised action arise. AAAP has undertaken significant benefit advocacy work in the South Auckland suburbs of Māngere and Clendon; areas which experience disproportionately high unemployment and poverty. The thousands of people AAAP benefit advocates supported in 2016 included over 700 people at a Benefit Impact event held at Māngere Work and Income in April: a three-day exercise where volunteer advocates supported people to access their benefit entitlements (Figure 1). The people supported in this way obtained 


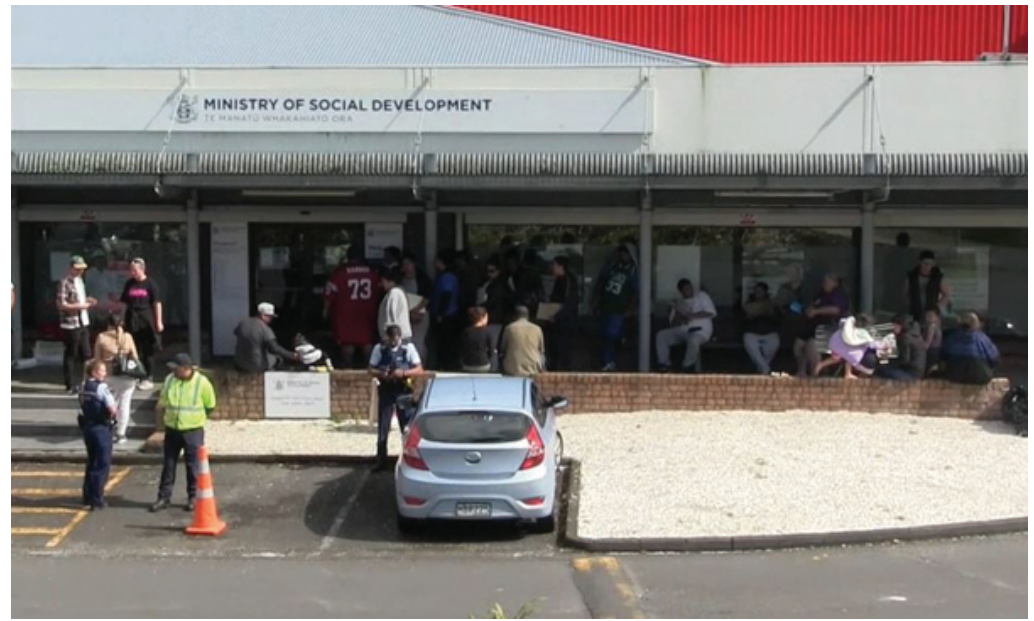

Figure 2. People Lined up Outside Clendon Work and Income getting Advocacy from AAAP with Police Present (28 October 2016)
(AAAP) has started helping beneficiaries there get what they are entitled to-but their presence has caused a stir. "The staff of the Ministry of Social Development are intimidated by the behavior of the crowd here," police told Newshub.

Last Friday police were called and people were threatened with trespass notices.

"They were telling us our mere presence was intimidating Work and Income staff and I find that bizarre," AAAP advocacy coordinator Alastair Russell said.

"We are here getting people what they are entitled to-if that's intimidation, then we are intimidating them and we will do that unapologetically."

Beneficiaries Newshub spoke to say the group have been a lifesaver, and that's why so many turn up.

The people at Clendon saw AAAP advocates stand with them in the face of police intimidation (Figure 2).

\section{Stop the Sanctions campaign}

Information gained through benefit advocacy leads to greater understanding of the oppression people experience and generates actions that challenge the status quo. At the 2016 Benefit Impact, it was apparent that there were significant numbers of sole-parent women who were having money deducted from their benefit because the father of at least one of their children was not legally named. An on-going sanction of $\$ 28$ per week per child is imposed.

There are over 13,000 parents with this sanction in place and over 17,000 children affected: $97.7 \%$ of the parents are women and $52.8 \%$ are Māori (Ministry of Social Development, 2016). This sanction is punitive, racist and sexist. The idea behind the sanction is that by punishing women, men will be made to be financially responsible for their 
children; Inland Revenue will be able to pursue the fathers for weekly Child Support payments. There are many reasons why a woman cannot name a child's father including simply not knowing who the father is, fear of violence, or the child coming from rape or incest. Each of these reasons should exclude the woman from the sanction, but this does not stop the sanction from being imposed.

To coincide with the Social Security Legislation Rewrite Bill, AAAP began the Stop the Sanctions campaign which is aimed at removing the sanction provisions contained within the re-write of the Social Security Bill (Figure 3). Pamphlets providing background information were distributed, community organisations provided support, submissions were made to the parliamentary Social Welfare Select Committee, political parties were lobbied, and a media campaign gained high-profile, national coverage.

At the time of writing we have the support of $60 \mathrm{MPs}$ in a parliament of 121 members. Advocates working with sole mothers have identified a clear pattern of institutional racism and patriarchy in the economic punishment of women and their children. Whilst this campaign continues, AAAP advocates are supporting women to have these sanctions stopped and to get Work and Income to re-pay money stolen from them.

\section{The state, precarious work and the poverty trap}

The Precariat, The New Dangerous Class (Standing, 2014) details the emergence of a new class of people who live a precarious life in the neoliberal economic world. One feature of this is their tenuous links to paid work. Employers, with backing from governments, demand a flexible workforce who will work when needed and workers have no rights to guaranteed hours or certainty of on-going employment.

Work and Income have the power to sanction (reduce benefit payments by $50 \%$ or $100 \%$ ) someone who does not accept an offer of

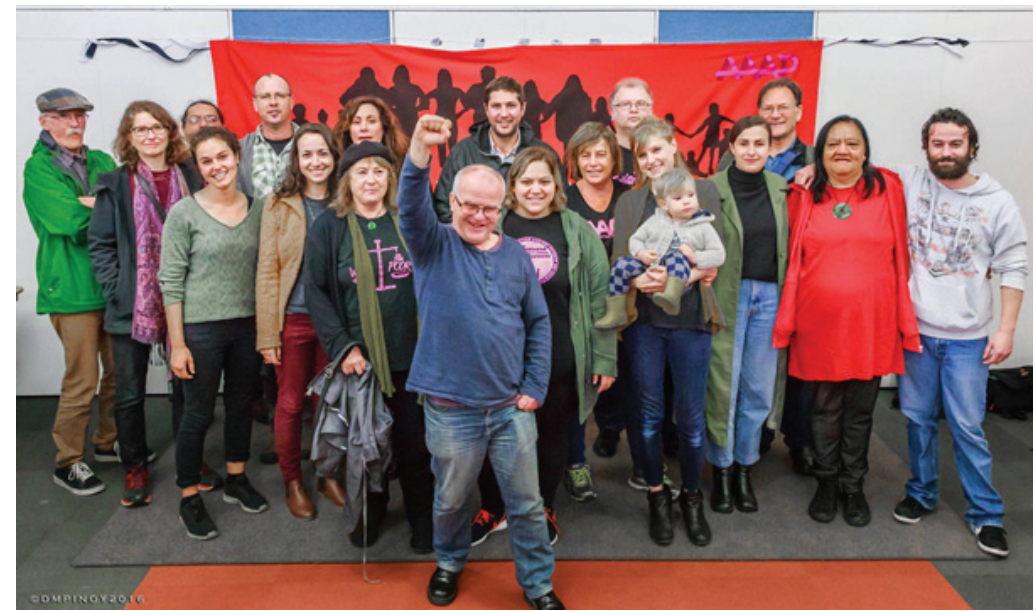

Figure 3. AAAP Members at the Launch of 'Stop the Sanctions' Campaign in Grey Lynn Community Centre (15 September 2016)

employment and can also impose standdowns of 13 weeks if someone voluntarily leaves a job. Work and Income also have contracts with recruitment companies to get people off the benefit. Unemployed people effectively have no choice but to agree to short-term work which keeps them in poverty whilst making money for recruitment companies. These companies receive payments from Work and Income and further fees from their client firms.

In a recent instance, the precarious work chain began at a Work and Income office where unemployed people were summoned to meet with a case manager who told them to sign a contract with Manpower, a multinational recruitment company, or face a benefit sanction. Manpower hired out the workers to Concentrix, a multinational call centre operator. Concentrix then hired out the workers to Spark. The workers can be dismissed or the work can simply stop without any notice or compensation. This involves two multi-national companies profiting from poverty and a large tele-communications company exploiting workers who are easily replaced by going back to the beginning of this exploitative chain at Work and Income. This is a poverty trap for the workers. 


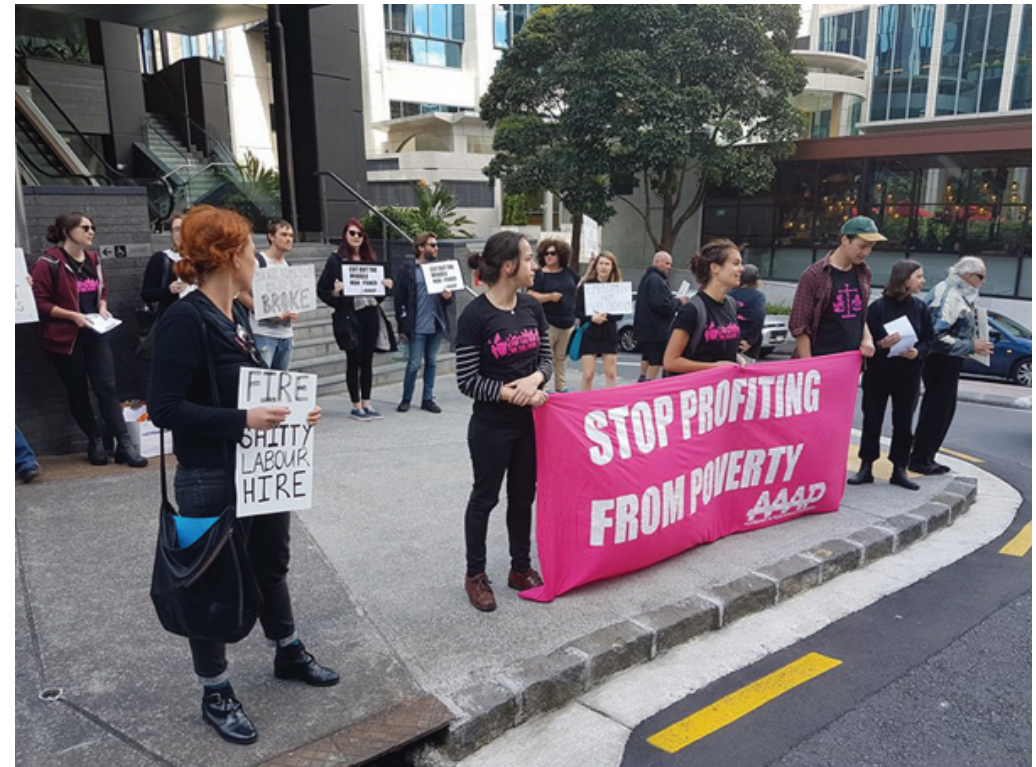

Figure 4. AAAP Members Supporting the Occupation of the Manpower offices in Auckland CBD (3 November 2016)
We wrote to Manpower telling them of our concerns. Manpower's response included an assurance that the contract we were concerned about was given by mistake. A different contract was supposed to have been used. TV3 news (Newshub) was contacted and a reporter asked for time to do background research including sending a reporter in to Manpower pretending to be looking for work. Subsequently that reporter was provided with the same contract that had been originally given to John.

Six weeks after our arrest for trespass, a group of workers who had all signed the same Manpower contract contacted AAAP. These workers had seen our protest action on TV and contacted us after being told there was no more work for them two weeks before Christmas. They had all been threatened with benefit sanctions by a case manager when presented with the Manpower contract. This contract was also the same as the one supposedly mistakenly given to John.

On Thursday, 3 November 2016, eight of us locked ourselves in at the Manpower office in central Auckland in a protest action that gained national media coverage (Figure 4).

This action began when a man, John (a pseudonym), contacted a AAAP benefit advocate to discuss a Manpower contract he had refused to sign, despite pressure to do so. He had been summoned to the Work and Income office and met with a case manager and someone from Manpower. John was concerned that many other people had succumbed to the threat of benefit sanction and had signed this contract. Many of those people subsequently contacted AAAP. John met with us and a lawyer from First Union. The lawyer provided a legal opinion indicating numerous breaches of the Employment Relations Act 2000 and the Holidays Act 2003 within the terms of the contract. A further document attached to the contract permitted Manpower to ask about John's political beliefs, union affiliations, sexual preferences and sexual practices.
Nine people who had lost their Manpower jobs came to the AAAP office the following day. A TV3 Newshub reporter interviewed some of the workers and the AAAP spokesperson (Barraclough, Redstall, \& Hollingworth, 2016). A Work and Income manager gave an assurance that none of the people who had lost their jobs would face any form of standdown or sanction. I went with a group of these now unemployed workers to the nearest Work and Income office to support them to get Food Grants and other immediate assistance.

After this second media wave, we met with the manager of Manpower Group, Australasia, and secured a written assurance that Manpower will no longer go into Work and Income offices to get people to sign contracts. First Union and AAAP also have a further meeting scheduled with the Recruitment and Consulting Services Association (an umbrella organisation for recruitment companies in Australia and New Zealand) in June 2017. John's courage 
and integrity in bringing this issue to AAAP generated a series of actions and contacts with exploited workers who wanted to engage in political actions to expose the actions of Work and Income and Manpower. Common interests were identified and acted upon, resulting in a multi-national company changing its practice. This is a significant victory.

Benefit advocacy work with individuals is inherently political within a competent solidarity frame and has come to be linked to a range of other strategies for political action. Competent solidarity involves working with people to address their personal circumstances and the ability and willingness to move on to take risks, maximise social change to address wider social justice issues.

\section{Options for the development of competent solidarity}

AAAP is distinct from other not-for-profit groups because we have a clear political analysis and use competent solidarity as the basis for all our work, providing an illustration of an alternative to neoliberal service delivery in social work. Social workers need to be able to link the experiences of the people they work with to the systemic causes of the oppression, identify who the oppressor is, how oppression happens and to act to challenge that oppression. Thus changing the interactions between social workers and the people they work with to become one of shared political interest-competent solidarity.

In December 2016, the International Association of Schools of Social Work and the International Federation of Social Workers released a Proposal for the Creation of a Committee in Defense of Social WorkersHuman Rights Defenders (Ioakimidis \& Hall, 2016). Internationally, social workers are imprisoned, tortured and killed because of their acts of solidarity. Acts of solidarity in Aotearoa/New Zealand are considerably less personally dangerous but are still essential.
Being able to address the most immediate financial needs of the people they are working with is a fundamental issue of credibility but this topic is neglected within social work education and consequently, social work practice. Many people come to AAAP because their social worker has not been able to support their right and need to access social welfare payments. In 2016, over 300 people attended benefit advocacy training run by AAAP; approximately half of these people were social workers. This should be mandatory.

For those currently employed as social workers, my immediate recommendation is join your union, demonstrate solidarity with the people you are working with and pursue shared political interests. Union meetings provide an opportunity to discuss social justice issues relevant to your workplace. As a union member, you have protections when your employer, who is likely to be one of the first agents of social control you will encounter, begins to tell you to adhere to the professional status quo aligned system they operate within.

The ANZASW code of ethics requires members to: "move from the private troubles they encounter with clients ... inform society at large about social injustice, and inform and enable social workers to effectively carry out their role and function" (ANZASW, 2007 , p. 8). This highlights the imperative to collectivise individual experiences to understand wider social issues. Carrying out a role or function where the private troubles and public issues are those of the client and not those of the social worker falls far short of the collective action provided within a competent solidarity framework.

The ANZASW code of ethics portrays the confusion within social work. Aspirations for social justice are thwarted by a professionalism which sees people as being clients seeking personal self-actualisation. In a world where people experience the oppression of neoliberal capitalism there is no room for confused social workers, 
distanced and separated from the people they are working with. It has been argued here that professional social work as a model of practice needs to be challenged and ultimately left behind as part of the baggage of neoliberalism. There is no better time than now to choose to be on the side of the oppressed. Take some well-considered risks and Stand Up, Speak Out, Fight Back.

\section{References}

Aotearoa New Zealand Association of Social Workers. (2007). Code of ethics. Wellington, NZ: Author.

Barraclough, B., Redstall, S., \& Hollingworth, A. (2016, December 13). Recruitment company Manpower accused of worker exploitation. Newshub. Retrieved from http://www.newshub.co.nz/home/money/2016/12/ recruitment-company-manpower-accused-of-workerexploitation.html

Came, H. (2012). Institutional racism and the dynamics of privilege in public health (Unpublished doctoral dissertation). University of Waikato, Hamilton, New Zealand.

loakimidis, V., \& Hall, N. (2016). Proposal for the creation of a Committee in Defense of Social Workers-Human Rights Defenders. Retrieved from https://www.academia. edu/30638008/Proposal_for_the_creation_of_a_ Committee_in_Defence_of_Social_Workers_Human_ Rights_Defenders

Ministry of Social Development. (2016, May 10). Information relating to reductions of the rates of benefits for sole parents under Section 70a of the Social Security Act. [Obtained under the Official Information Act 1982. Request to the Ministry of Social Development].

McRae, T. (2016, November 25). Police called on beneficiaries seeking entitlements. Newshub. Retrieved from http://www.newshub.co.nz/home/ new-zealand/2016/11/police-called-on-group-helpingbeneficiaries-get-entitlements.html

Rogowski, S. (2017, January 2). Untitled. Rebel social work. Retrieved from https://www.facebook.com/groups/ rebelsocialwork/

Standing, G. (2014). The Precariat: The new dangerous class. London, UK: Bloomsbury. 